\title{
Assessment of the conventional radial artery with optical coherent tomography after the snuffbox approach
}

\author{
Yongcheol Kim ${ }^{1,2}$, Sang Yeub Lee ${ }^{3,4}$, Dae In Lee ${ }^{3}$, Ju-Hee Lee ${ }^{3}$, Sang Min Kim³
} Jang-Whan Bae ${ }^{3,4}$, Kyung-Kuk Hwang ${ }^{3,4}$, Dong-Woon Kim ${ }^{3,4}$, Myeong-Chan $\mathrm{Cho}^{3,4}$, Myung Ho Jeong ${ }^{2}$

${ }^{1}$ Division of Cardiology, Department of Internal Medicine, Yonsei University College of Medicine and Cardiovascular Center, Yongin Severance Hospital, Yongin, Korea

${ }^{2}$ Division of Cardiology, Chonnam National University Hospital, Gwangju, Korea

${ }^{3}$ Regional Cardiovascular Disease Center, Chungbuk National University Hospital, Cheongju, Korea ${ }^{4}$ Department of Internal Medicine, College of Medicine, Chungbuk National University, Cheongju, Korea

\begin{abstract}
Background: This study aimed to evaluate acute injuries of the radial artery (RA) using optical coherence tomography (OCT) in patients who underwent coronary intervention via the snuffbox approach.

Methods: Forty-six patients, who underwent coronary intervention and assessment of the conventional $R A$ using OCT via the snuffbox approach, were enrolled from two university hospitals between August 2018 and August 2019.

Results: The mean age of the patients was 65.1 years. In this study population, 6-French (Fr) sheaths were used. The mean diameter of the conventional $R A$ was $2.89 \pm 0.33 \mathrm{~mm}$, and the mean lumen area of the conventional $R A$ was $6.68 \pm 1.56 \mathrm{~mm}^{2}$. Acute injuries of the conventional $R A$, after the snuffbox approach, were observed in 5 (10.9\%) patients. Intimal tear was observed in the RA in 1 (2.2\%) case. Intraluminal thrombi, without vessel injuries, were detected in the RA in 4 (8.7\%) cases. However, medial dissection was not observed in the OCT analysis.

Conclusions: This retrospective OCT-based study showed that the diameter of the conventional RA was $2.89 \mathrm{~mm}$ and acute vessel injury of the conventional $R A$ was rare in patients who underwent coronary intervention via the snuffbox approach. (Cardiol J 2021; 28, 6: 849-854)

Key words: anatomical snuffbox, radial artery occlusion, optical coherence tomography
\end{abstract}

\section{Introduction}

The transfemoral approach has traditionally been used as the route for coronary intervention as a larger guiding catheter can be used and good back-up support is available for this approach; moreover, the approach is also convenient for the operator. Since the first percutaneous coronary intervention $(\mathrm{PCI})$ via the conventional transra- dial approach (cTRA) performed by Kiemeneij and Laarman in 1993, the use of cTRA has gradually increased [1]. The cTRA is associated with a lower rate of serious access-site complications and improved patient comfort compared to the transfemoral approach $[2,3]$. The cTRA has become essential for coronary angiography (CAG) and PCI and is the default access-site route used in daily practice. It is recommended as the standard

Address for correspondence: Sang Yeub Lee, MD, PhD, Division of Cardiology, Department of Internal Medicine, College of Medicine, Chungbuk National University, 776, 1Sunhwan-ro, Seowon-gu, Cheongju-si, Chungcheongbuk-do 28644, Korea, e-mail: louisahj@gmail.com

Received: 14.03.2020 Accepted: 13.07.2020 Early publication date: 21.07.2020

This article is available in open access under Creative Common Attribution-Non-Commercial-No Derivatives 4.0 International (CC BY-NC-ND 4.0) license, allowing to download articles and share them with others as long as they credit the authors and the publisher, but without permission to change them in any way or use them commercially. 


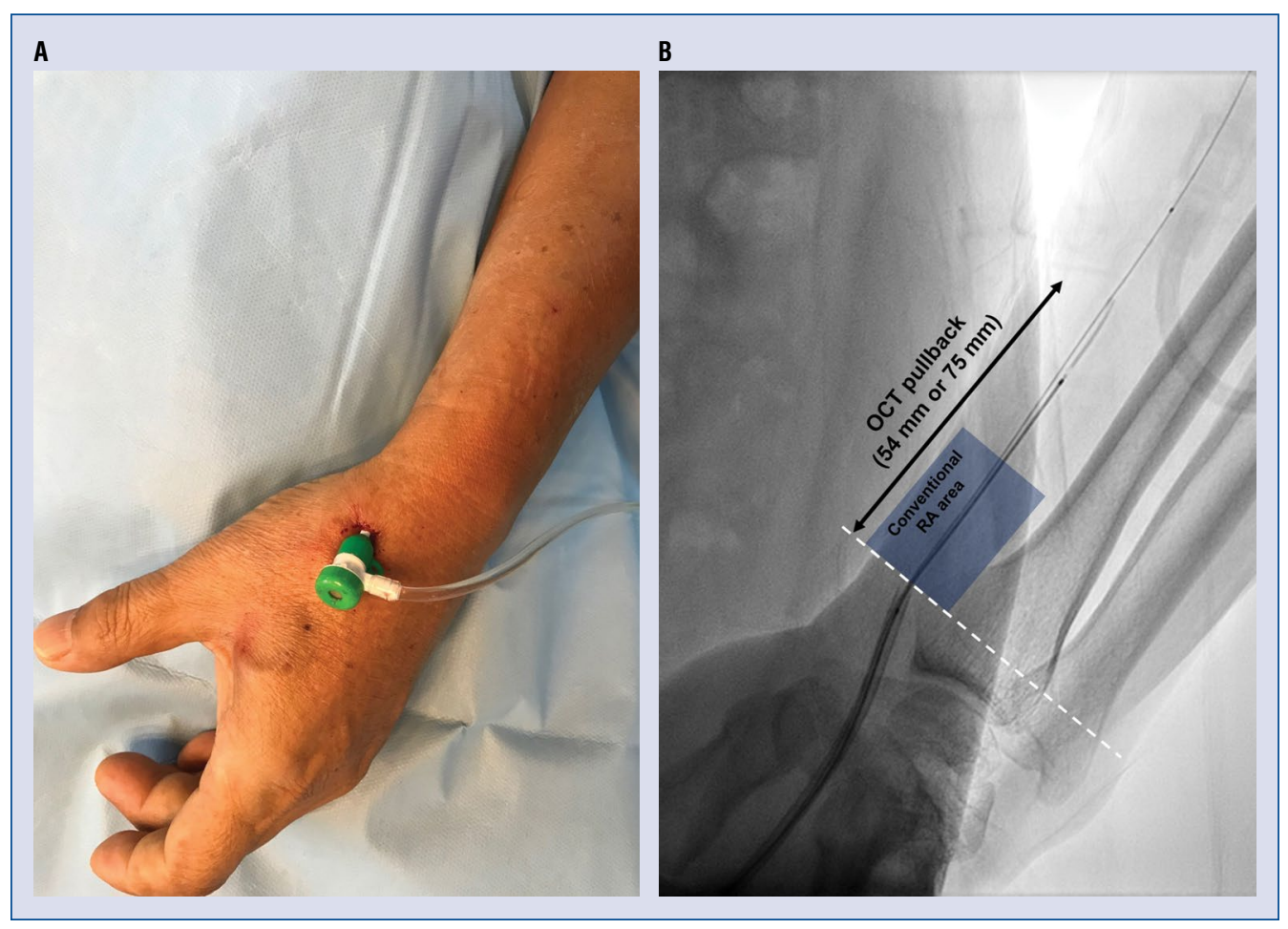

Figure 1. A 6-Fr sheath is inserted via the distal radial approach $(\mathbf{A})$ and the conventional radial artery $(\mathrm{RA})$ is assessed with optical coherence tomography (OCT; B). (White dotted line: distal margin of the conventional RA).

approach for PCI in most clinical settings, including acute myocardial infarction $[4,5]$. However, damage to the puncture site is inevitable, and there is still concern for radial arterial occlusion (RAO) [6]. In addition, the cTRA is associated with potential risks of functional and anatomical injuries in future candidates of hemodialysis access and bypass grafts for surgical revascularization [7].

The distal radial approach, called the snuffbox approach, is a relatively novel technique that has attracted the interest of interventional cardiologists [8]. The incidence of RAO may decrease using this approach due to the availability of a dual supply system with no direct cannulation injury of the conventional radial artery (RA) [9]. However, limited data are available regarding the incidence of complications with this new puncture technique, especially acute injury of the RA after coronary intervention via the snuffbox approach.

Optical coherence tomography (OCT) is an imaging technique and is currently the best modality for assessing subtle damages (e.g., intimal and medial layer injuries) at high-resolution $(10 \mu \mathrm{m})$ $[10,11]$. This imaging modality can clearly reveal significant acute injuries and chronic intimal thickening of the RA after the cTRA [12]. However, the assessment of acute RA injuries after the snuffbox approach using OCT has not been reported to date. Therefore, this study aimed to evaluate the conventional RA after the snuffbox approach by qualitative and quantitative OCT analysis.

\section{Methods}

\section{Study population}

Patients who underwent coronary intervention under OCT guidance via the snuffbox approach at two hospitals were included. Those who had previously undergone CAG or PCI via the conventional radial approach were excluded. A single operator at each hospital performed the snuffbox approach in patients who had a palpable distal RA in the anatomical snuffbox area. The study protocol was approved by the Institutional Review Board of Chungbuk National University Hospital and Chonnam National University Hospital (approval number: CNUH-2019-272, CBNUH-2019-10-019).

\section{Puncture and cannulation at the anatomical snuffbox}

After local anesthesia, with $1 \mathrm{~mL}$ lidocaine hydrochloride using a 26 -gauge needle, was administered to the anatomical snuffbox area, the puncture was performed using a 21-gauge open 


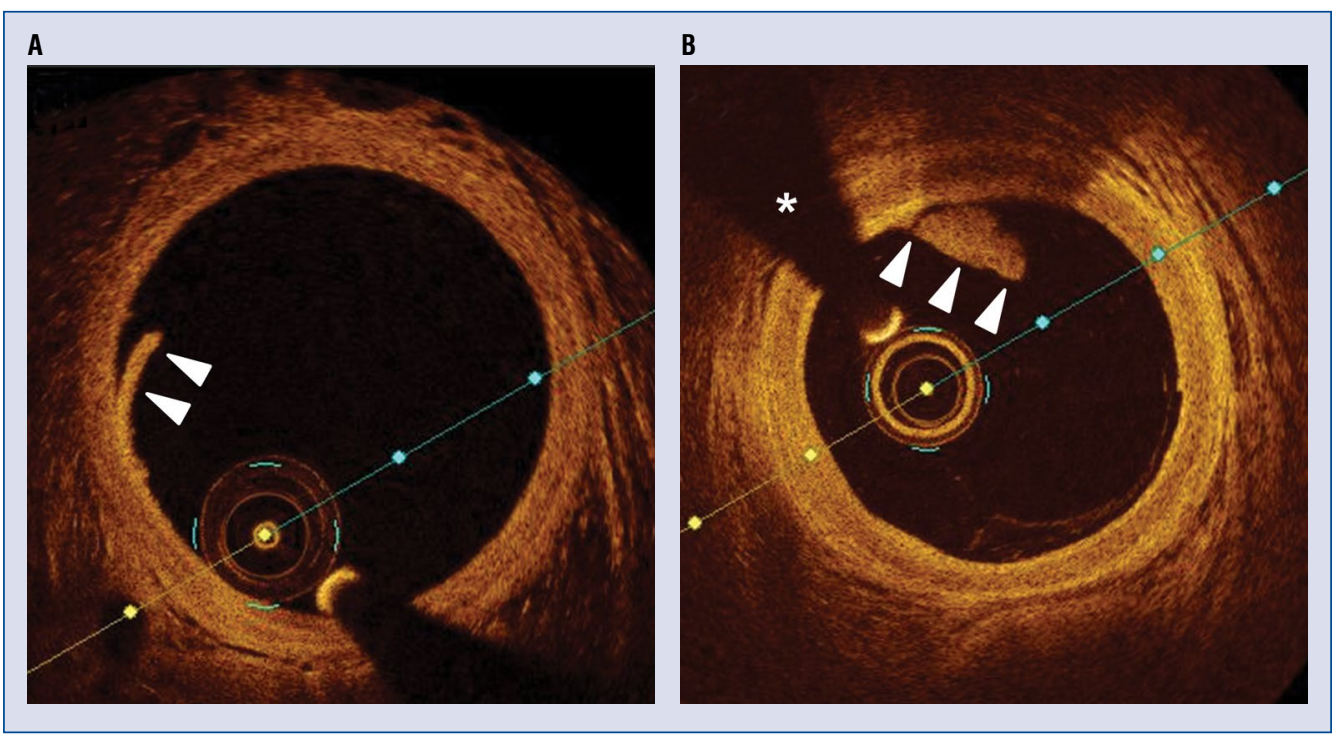

Figure 2. Optical coherence tomography image of the conventional radial artery, showing an intimal tear (A, arrowheads), intraluminal thrombus (B, arrowheads; wire artifact - asterisk).

needle using the anterior puncture technique. A 0.018 -inch hair wire was then introduced after successful puncture, followed by the insertion of a 6-French (Fr) radial sheath (Prelude Radial ${ }^{\circledR}$, Merit Medical, Utah, USA) (Fig. 1A). Following successful cannulation in the snuffbox area, a solution containing $0.2 \mathrm{mg}$ of nitroglycerin, $2.5 \mathrm{mg}$ of verapamil, and 3,000 units of unfractionated heparin (diluted in $10 \mathrm{~mL}$ of saline solution) was injected in all study participants to prevent arterial spasms and thrombosis. Anticoagulation with a bolus of unfractionated heparin (75-100 U/kg) was administered to achieve an activated clotting time $>300$ s during PCI.

\section{Hemostasis}

After the puncture procedure was completed, hemostasis was achieved by applying sterile 4 " $\times 4$ " gauze and self-adherent bandages for $3 \mathrm{~h}$. Hemostasis was evaluated by the operator; when hemostasis was successfully achieved, the bandage could be removed. If hemostasis was not achieved, the gauze and bandages were applied for an additional 30-60 min.

\section{OCT image acquisition and analysis}

The OCT system used in this study was The Dragonfly $^{\mathrm{TM}}$ OPTIS $^{\mathrm{TM}}$ Imaging Catheter (Abbott, St. Paul, Minnesota, USA) with OPTIS analysis software. Obtaining an OCT image of RA was done in patients who underwent successful PCI. Before the OCT examination for conventional RA, the introducer sheath was pulled out when the tip reached the dorsal tubercle of the radius; this was defined as the distal margin of the conventional RA area, based on a previous study (Fig. 1B) [13]. Then, $54 \mathrm{~mm}$ or $75 \mathrm{~mm}$ OCT pullback was conducted. During the OCT pullback, $5 \mathrm{cc}$ of contrast media was manually injected via the radial sheath. After acquisition of the OCT images of the RA, cross-sectional OCT images on conventional $\mathrm{RA}$ area were analyzed at $1-\mathrm{mm}$ intervals of the intravascular image core laboratory at the Chonnam National University Hospital. An intimal tear was defined as luminal surface discontinuity, with or without an intimal flap, that was restricted within the intima (Fig. 2A). Medial dissection was defined as luminal surface disruption that extended into the media, either in the radial or the circumferential direction [12]. The presence of a thrombus was also assessed; a thrombus was defined as highbackscattering protrusions inside the lumen of the artery in the OCT image (Fig. 2B) [14]. Qualitative assessment of acute injury of the conventional RA was performed using whole OCT pullback images for each patient. With respect to the quantitative assessment, the regions within $30 \mathrm{~mm}$ of the conventional RA area were assessed on the OCT images, as shown Figure 1B.

\section{Data collection and statistical analysis}

Patient demographic data, including age, gender, height, weight, body mass index, current smoking status, and medical history, including 
prevalence of hypertension, diabetes mellitus, and dyslipidemia were recorded. The data on coronary angiographic and procedural characteristics during the snuffbox approach were recorded.

The continuous variables were analyzed using the paired $t$-test; they were expressed as the mean with standard deviation. For categorical variables, data were expressed as counts with percentages. Statistical analysis was performed using SPSS 22.0 for Windows (SPSS-PC, Chicago, IL, USA).

\section{Results}

Baseline and procedural characteristics

Forty-six patients who underwent coronary intervention and assessment of the conventional RA with OCT via the snuffbox approach were enrolled from two university hospitals between August 2018 and August 2019. The baseline clinical and procedural characteristics of the study population are summarized in Table 1 . The mean age of the patients was 65.1 years, and $84.8 \%$ were male. A total of $30(65.2 \%)$ patients underwent coronary intervention for acute coronary syndrome, including 4 patients with ST-segment elevation myocardial infarction. The left snuffbox approach was selected for $31(67.4 \%)$ patients. All coronary interventions via the snuffbox approach were performed using a 6-Fr sheath. There were 26 (59.1\%) patients with lesions in the left anterior descending coronary artery and $3(6.8 \%)$ patients with lesions in the left main artery.

\section{Qualitative and quantitative assessment} of the conventional RA with OCT (Table 2)

The number of total cross-sections analyzed for the study population was 2491 frames. For each $\mathrm{RA}$, the mean number of RA cross-sections analyzed was $27.7 \pm 5.1$ frames. The mean diameter of the conventional RA was $2.89 \pm 0.33 \mathrm{~mm}$, and the mean lumen area of the conventional RA was $6.68 \pm 1.56 \mathrm{~mm}^{2}$.

Acute injuries of the conventional RA after the snuffbox approach were observed in $5(10.9 \%)$ patients. Intimal tears were observed in the RA in $1(2.2 \%)$ case. Intraluminal thrombi, without vessel injury, were detected in the RA in $4(8.7 \%)$ cases. However, medial dissections were not observed in the OCT analyses.

\section{Discussion}

In the present study, the diameter and the lumen area of the conventional RA, as assessed by
Table 1. Baseline and procedural characteristics of the study population.

\begin{tabular}{lc}
\hline Clinical characteristics $(\mathbf{n}=46)$ & Value \\
\hline Age [years] & $65.1 \pm 10.3$ \\
Male & $39(84.85)$ \\
BMI $\left[\mathrm{kg} / \mathrm{m}^{2}\right]$ & $24.0 \pm 2.9$ \\
BSA $\left[\mathrm{m}^{2}\right]$ & $1.78 \pm 0.16$ \\
Hypertension & $49(49.0 \%)$ \\
Diabetes mellitus & $30(30.0 \%)$ \\
Dyslipidemia & $33(33.0 \%)$ \\
Current smoking & $51(51.0 \%)$ \\
LVEF [\%] & $63.7 \pm 10.7$ \\
Serum creatinine [mg/dL] & $1.0 \pm 0.8$ \\
Indication: & $100(100 \%)$ \\
Stable angina pectoris & $16(34.8 \%)$ \\
NSTE-ACS & $26(56.5 \%)$ \\
STEMI & $4(8.7 \%)$ \\
Left snuffbox approach & $31(67.4 \%)$ \\
Use of 6-Fr sheath & $46(100 \%)$ \\
Target vessel (n = 44): & \\
Left anterior descending artery & $26(59.1 \%)$ \\
Left circumflex artery & $7(15.9 \%)$ \\
Right coronary artery & $8(18.2 \%)$ \\
Left main artery & $3(6.8 \%)$ \\
Stent implantation & $42(91.3 \%)$ \\
\hline
\end{tabular}

Values are presented as mean \pm standard deviation or number $(\%)$; $\mathrm{BMI}$ - body mass index; BSA — body surface area; LVEF — left ventricular ejection fraction; NSTE-ACS - non-ST-segment elevation acute coronary syndrome; STEMI - ST-segment elevation myocardial infarction

Table 2. Evaluation of radial artery (RA) by optical coherence tomography $(n=46)$.

\begin{tabular}{lc}
\hline Parameters & Value \\
\hline $\begin{array}{l}\text { Number of total analyzed cross } \\
\text { sections [frame] }\end{array}$ & 2491 \\
$\begin{array}{l}\text { Mean length of cross sections } \\
\text { of analyzed RA [mm] }\end{array}$ & $27.7 \pm 5.1$ \\
$\begin{array}{l}\text { Mean diameter of conventional } \\
\text { RA [mm] }\end{array}$ & $2.89 \pm 0.33$ \\
$\begin{array}{l}\text { Mean lumen area of conventional } \\
\text { RA [mm }{ }^{2} \text { ] }\end{array}$ & $6.68 \pm 1.56$ \\
$\begin{array}{l}\text { Acute injury of RA after snuffbox } \\
\text { approach: } \\
\text { Intimal tear } \\
\text { Intraluminal thrombus }\end{array}$ & $5(10.9 \%)$ \\
$\quad$ Medial dissection & $1(2.2 \%)$ \\
\hline
\end{tabular}

Values are presented as mean \pm standard deviation or number (\%).

OCT, were $2.89 \pm 0.33 \mathrm{~mm}$ and $6.68 \pm 1.56 \mathrm{~mm}^{2}$, respectively. Moreover, among 46 OCT pullback 
images of the RA, acute vessel injury of the conventional RA was rarely observed. There was only 1 case of intimal tear (2.2\%); although, 4 cases of intraluminal thrombi, without vessel injury (8.7\%), were observed. According to available research, this is the first study to evaluate acute injury of the conventional RA with OCT after coronary intervention via the snuffbox approach.

Several studies have reported on the diameter of the RA. In a previous study, the diameter of the conventional RA was $2.72 \mathrm{~mm}$ in Korean patients, as noted with quantitative coronary angiography (QCA) [13]. In other studies, the diameter of the conventional RA was reported to be $2.7-3.1 \mathrm{~mm}$, as assessed by vascular ultrasonography [15-17]. These findings were similar to the present RA diameter findings. However, several studies reported the lumen diameter measured using QCA was significantly smaller, approximately $5 \%$ smaller, compared to that determined using OCT $[18,19]$. Therefore, the accurate RA diameter measured using OCT in the present study is expected to aid interventional cardiologists.

Several studies have reported that the occurrence of conventional RAO was rare, confirmed by vascular ultrasonography, after the snuffbox approach $(0.27 \%, 1 / 366)[8,16,17]$. Mizuguchi et al. [16] reported that the incidence of conventional RAO at 1 -month, as evaluated by vascular sonography, was very rare $(0.4 \%, 1 / 228)$. Moreover, snuffbox approach does not lead to direct damage of the conventional RA by arterial puncture and sheath insertion. Therefore, it is expected that the snuffbox approach would be beneficial for patients with end-stage renal disease (ESRD) or chronic kidney disease (CKD) in whom the RA must be preserved for the creation of the arteriovenous fistula. The protection of the RA by the snuffbox approach is expected; however, no studies have assessed the conventional RA using intravascular imaging modalities. OCT can provide superior resolution $(10 \mu \mathrm{m})$ for the visualization of the three layers of the artery: the intima, media, and adventitia [20,21]. OCT evaluated the whole RA at the conventional radial puncture site in the present study and it clearly demonstrated that acute vessel injury of the RA after the snuffbox approach was infrequent. Therefore, this study reaffirms the potential benefits of the snuffbox approach in terms of the preservation of the conventional RA and the feasible access-site for $\mathrm{CAG}$ or $\mathrm{PCI}$ in patients with CKD or ESRD.

\section{Limitations of this study}

There are several limitations of the present study. First, for each patient, the snuffbox approach was performed by a single experienced radial operator at each hospital. Second, this study did not have a control group. Therefore, some selection bias may have influenced the results. Third, inter-observer and intra-observer variability of OCT analysis were not evaluated. Fourth, only Korean patients were enrolled in this study. Fifth, short-term or long-term patency of RA with using vascular ultrasound was not evaluated. Thus, the present results should be carefully interpreted. Despite these limitations, the study findings are expected to aid physicians in understanding the feasibility of the snuffbox approach for the preservation of the conventional RA.

\section{Conclusions}

This retrospective OCT-based study indicated that the diameter of the conventional RA was $2.89 \pm 0.33 \mathrm{~mm}$ and that acute vessel injury of the conventional RA was rare in patients who underwent coronary intervention via the snuffbox approach. In the future, a large prospective multi-national study is needed to evaluate the long-term patency of conventional RA after the snuffbox approach.

\section{Acknowledgments}

The authors would like to thank the staff, especially Young Hun Jin, at the cardiac catheterization laboratories at Chonnam National University Hospital and Chungbuk National University Hospital for their commitment to this study.

\section{Conflict of interest: None declared}

\section{References}

1. Kiemeneij F, Laarman GJ. Percutaneous transradial artery approach for coronary stent implantation. Cathet Cardiovasc Diagn. 1993; 30(2): 173-178, doi: 10.1002/ccd.1810300220, indexed in Pubmed: 8221875.

2. Agostoni P, Biondi-Zoccai GGL, de Benedictis ML, et al. Radial versus femoral approach for percutaneous coronary diagnostic and interventional procedures; Systematic overview and meta-analysis of randomized trials. J Am Coll Cardiol. 2004; 44(2): 349-356, doi: 10.1016/j.jacc.2004.04.034, indexed in Pubmed: 15261930.

3. Valgimigli M, Gagnor A, Calabró P, et al. MATRIX Investigators. Radial versus femoral access in patients with acute coronary syndromes undergoing invasive management: a randomised multicentre trial. Lancet. 2015; 385(9986): 2465-2476, doi: 10.1016/ S0140-6736(15)60292-6, indexed in Pubmed: 25791214. 
4. Ibanez B, James S, Agewall S, et al. 2017 ESC Guidelines for the management of acute myocardial infarction in patients presenting with ST-segment elevation: The Task Force for the management of acute myocardial infarction in patients presenting with ST-segment elevation of the European Society of Cardiology (ESC). Eur Heart J. 2018; 39(2): 119-177.

5. Neumann FJ, Sousa-Uva M, Ahlsson A, et al. 2018 ESC/EACTS Guidelines on myocardial revascularization. Eur Heart J. 2019; 40(2): 87-165.

6. Avdikos G, Karatasakis A, Tsoumeleas A, et al. Radial artery occlusion after transradial coronary catheterization. Cardiovasc Diagn Ther. 2017; 7(3): 305-316, doi: 10.21037/cdt.2017.03.14, indexed in Pubmed: 28567356.

7. Possati G, Gaudino M, Prati F, et al. Long-term results of the radial artery used for myocardial revascularization. Circulation. 2003; 108(11): 1350-1354, doi: 10.1161/01.CIR.0000087402.13786.D0, indexed in Pubmed: 12939220.

8. Kiemeneij F. Left distal transradial access in the anatomical snuffbox for coronary angiography (ldTRA) and interventions (ldTRI). EuroIntervention. 2017; 13(7): 851-857, doi: 10.4244/ EIJ-D-17-00079, indexed in Pubmed: 28506941.

9. Babunashvili A, Dundua D. Recanalization and reuse of early occluded radial artery within 6 days after previous transradial diagnostic procedure. Catheter Cardiovasc Interv. 2011; 77(4): 530-536, doi: 10.1002/ccd.22846, indexed in Pubmed: 20939038.

10. Kim Y, Johnson TW, Akasaka T, et al. The role of optical coherence tomography in the setting of acute myocardial infarction. J Cardiol. 2018; 72(3): 186-192, doi: 10.1016/j.jjcc.2018.03.004, indexed in Pubmed: 29650398.

11. Kim Y, Hong Y, Kim S, et al. Impact of combination therapy with ezetimibe/simvastatin treatment on the neointimal response to biodegradable polymer biolimus-eluting stent implantation in patients with acute myocardial infarction: serial assessment with optical coherence tomography. Applied Sciences. 2018; 8(10): 1968, doi: 10.3390/app8101968.

12. Yonetsu T, Kakuta T, Lee T, et al. Assessment of acute injuries and chronic intimal thickening of the radial artery after transradial coronary intervention by optical coherence tomography. Eur Heart J. 2010; 31(13): 1608-1615, doi: 10.1093/eurheartj/ehq102, indexed in Pubmed: 20413398.
13. Kim Y, Jeong MHo, Kim MC, et al. Feasibility of coronary angiography and percutaneous coronary intervention via left snuffbox approach. Korean Circ J. 2018; 48(12): 1120-1130, doi: 10.4070/ kcj.2018.0181, indexed in Pubmed: 30088362.

14. Kume T, Akasaka T, Kawamoto T, et al. Assessment of coronary arterial thrombus by optical coherence tomography. Am J Cardiol. 2006; 97(12): 1713-1717, doi: 10.1016/j.amjcard.2006.01.031, indexed in Pubmed: 16765119.

15. Lee JW, Park SW, Son JW, et al. Real-world experience of the left distal transradial approach for coronary angiography and percutaneous coronary intervention: a prospective observational study (LeDRA). EuroIntervention. 2018; 14(9): e995-e99e1003, doi: 10.4244/EIJ-D-18-00635, indexed in Pubmed: 30222122.

16. Mizuguchi Y, Izumikawa T, Hashimoto S, et al. Efficacy and safety of the distal transradial approach in coronary angiography and percutaneous coronary intervention: a Japanese multicenter experience. Cardiovasc Interv Ther. 2020; 35(2): 162-167, doi: 10.1007/s12928-019-00590-0, indexed in Pubmed: 31127474.

17. Norimatsu K, Kusumoto T, Yoshimoto K, et al. Importance of measurement of the diameter of the distal radial artery in a distal radial approach from the anatomical snuffbox before coronary catheterization. Heart Vessels. 2019; 34(10): 1615-1620, doi: 10.1007/s00380-019-01404-2, indexed in Pubmed: 30972548.

18. Kubo T, Akasaka T, Shite J, et al. OCT compared with IVUS in a coronary lesion assessment: the OPUS-CLASS study. JACC Cardiovasc Imaging. 2013; 6(10): 1095-1104, doi: 10.1016/j. jcmg.2013.04.014, indexed in Pubmed: 24011777.

19. Gutiérrez-Chico JL, Serruys PW, Girasis C, et al. Quantitative multi-modality imaging analysis of a fully bioresorbable stent: a head-to-head comparison between QCA, IVUS and OCT. Int J Cardiovasc Imaging. 2012; 28(3): 467-478, doi: 10.1007/s10554011-9829-y, indexed in Pubmed: 21359517.

20. Kim Y, Jeong MHo, Kim MC, et al. Assessment for ambiguous angiographic finding in patient with acute myocardial infarction by optical coherence tomography. Cardiol J. 2018; 25(4): 536-537, doi: 10.5603/CJ.2018.0086, indexed in Pubmed: 30211933.

21. Kim Y, Johnson TW, Park SH, et al. Optical coherence tomography findings of non-st elevation myocardial infarction with multivessel disease. Korean Circ J. 2020; 50(1): 88-90, doi: 10.4070/ kcj.2019.0222, indexed in Pubmed: 31854159. 